\title{
CORRECTION
}

\section{Correction to: Conventional displays of structures in data compared with interactive projection-based clustering (IPBC)}

\author{
Michael C. Thrun ${ }^{1,3}$ (1) $\cdot$ Felix Pape ${ }^{2} \cdot$ Alfred Ultsch $^{2}$
}

Published online: 2 August 2021

(c) Springer Nature Switzerland AG 2021

\section{Correction to: \\ International Journal of Data Science and Analytics https://doi.org/10.1007/s41060-021-00264-2}

In the original article, the corresponding author affiliation published incorrectly. The correct affiliation is IAP-GmbH Intelligent Analytics Projects, In den Birken 10A, 29352 Adelheidsdorf.

The original article has been updated.

Publisher's Note Springer Nature remains neutral with regard to jurisdictional claims in published maps and institutional affiliations.

The original article can be found online at https://doi.org/10.1007/ s41060-021-00264-2.

Michael C. Thrun

mthrun@informatik.uni-marburg.de

1 IAP-GmbH Intelligent Analytics Projects, In den Birken 10A, 29352 Adelheidsdorf, Germany

2 Philipps-University of Marburg, 35032 Marburg, Germany

3 Department of Hematology, Oncology and Immunology, Philipps-University of Marburg, Marburg, Germany 